\title{
Pertinencia y Funcionalidad DEL JUICIO DE VALOR \\ EN LAS EXPLICACIONES NARRATIVAS \\ DE LA HISTORIOGRAFÍA*
}

Luciano P.J. Alonso**

1.

La cuestión relativa a la pertinencia y funcionalidad de los de juicios de valor en la historiografia no parece guardar actualidad. Desde ciertos posicionamientos constituiría ya un problema definido, casi remanido; desde otros, resulta en un todo intrascendente.

Tanto el positivismo académico como la teoría social clásica postularon una separación tajante entre constatación y explicación de hechos por un lado y valoraciones de esos hechos por el otro. La asepsia positivista implica la negativa a reconocer los propios valores insertos en el conocimiento científico por procedimientos racionales y someterlos a crítica, con lo cual se ocultan las facetas ideológicas del conocimiento y se torna imposible el desarrollo de modos de significación que impugnen las relaciones de dominación existentes. "La economía de la elección de medios racionales para fines dados - dice Habermas-, garantizada por prognosis condicionales en forma de recomendaciones técnicas, es el único 'valor'

* Este texto es una versión ampliada de la ponencia El juicio de valor en las explicaciones narrativas de la historiografia, presentada en las "VII Jornadas Interescuelas/Departamentos de Historia", Universidad Nacional del Comahue, Neuquén, setiembre de 1999.

** Centro de Estudios Sociales Interdisciplinarios del Litoral, Facultad de Formación Docente en Ciencias, Universidad Nacional del Litoral. 
permitido, y ni siquiera es defendido explícitamente como valor, porque se presenta como coincidente con la racionalidad pura y simple. En realidad se trata, sin embargo, de la formalización de una sola referencia de la vida, a saber, la experiencia de los controles de resultados incorporados en los sistemas de trabajo social y practicados ya en todo acto elemental de trabajo".(1) La racionalidad tecnológica aparece como único valor, porque ella misma es racional y por tanto puede presentarse como axiológicamente "neutra". De esta manera determinados juicios de valor se toman como axiomas que por la naturalización del procedimiento se sustraen a todo debate racional. Podríamos multiplicar los ejemplos de este tipo de operaciones de asignación de valor en la historiografia, desde la naturalización retrospectiva de las relaciones de mercado a la justificación encubierta de la dominación de las élites bajo principios de organización de la sociedad.

El ataque más co:nsecuente y mejor fundado que se realizara dentro de la tradición de la teoría social clásica contra la enunciación de juicios de valor en el discurso científico $-y$ por consiguiente contra toda posibilidad de una teoría social verdaderamente crítica-, fue formulado por Max Weber en diversos escritos teórico-metodológicos. Weber desarrolló a lo largo de al menos dos decenios un intento de separar la validez de un imperativo práctico en cuanto norma y el valor de verdad de una comprobación empírica de hechos. De tal manera, trató de distinguir por un lado las "valoraciones" derivadas de la subjetividad individual -entendidas como "... evaluaciones prácticas del carácter censurable o digno de aprobación de los fenómenos influibles por nuestro actuar"-, ${ }^{(2)}$ y por el otro los enunciados positivos sobre la realidad derivables de la aplicación de un método científico que aseguraría su objetividad. Las "ciencias histórico-sociales", para él, no debían recurrir a presupuestos que implicaran una toma de posición valorativa a los fines de mantener esa objetividad, lo que significa que no deben formularse juicios de valor y que sus resultados no pueden convertirse en base de una ética de la intención o mejor, en lo que le preocupaba a Weber, en base de una posición política.

Esa tradicional asepsia valorativa es hoy abandonada como corolario lógico de un relativismo que se puede rastrear tanto en el decisionismo de Raymond Aron, (3) como en el impacto de la hermenéutica constitutiva propia de una antropología que hace hincapié en la alteridad irreductible de la experiencia cultural - ejemplificada por los trabajos de Peter Winch y Clifford Geertz-. A su vez, por el lado de una filosofia de la historia que se autodenomina frecuentemente "posmodernista", pierden todo interés las cuestiones no sólo relativas a la enunciación de juicios de valor sino a la misma veracidad del discurso historiográfico, y por tanto a las operaciones de explicación, argumentación y justificación. ${ }^{(4)}$ En consecuencia los valores son concebidos como un aspecto más de la inconmensurabilidad cultural -cuando no resultarían formas hipócritas del poder-, con lo que se torna imposible sostener juicios válidos sobre una realidad extratextual. 
Frente a estos posicionamientos, aquella historiografia que defiende la posibilidad de constituir un espacio de crítica de la dominación y por tanto de crítica de la ideología como modo en que el significado sirve para sostener las relaciones de dominación, ${ }^{(5)}$ no puede eludir el tratamiento de los problemas relativos a la asignación de valor. El desarrollo de una teoría social crítica y de una historiografia a ella asociada que contribuya a esclarecer procesos concretos de la vida social, requiere del intento de develar los juicios de valor subyacentes en los discursos sociales y en el discurso científico en particular -incluyendo sus propios enunciados- y de proponer nuevos juicios de valor. ${ }^{(6)}$ Resulta entonces necesario intentar la clarificación de las funciones que los juicios de valor pueden cumplir con respecto a los procesos de explicación/comprensión.

\section{2.}

Aunque existen variadas concepciones de lo que significa "explicar" un fenómeno o tipo de fenómenos, se acepta normalmente que el pensamiento científico desarrolla diversos tipos de explicación como forma de deducir unos enunciados de otros con el resguardo de ciertos requisitos formales y procedimientos de corroboración. En otras palabras, explicar implica derivar consecuencias de premisas en el marco de una justificación teórica y a través de enunciados fundados en razones suficientes - o mejor, que provisoriamente se entienden suficientes-. En términos de Félix Schuster, los componentes de una explicación tienen que satisfacer condiciones de adecuación lógica y empírica, que es dable resumir como condiciones de deductibilidad y de puesta a prueba mediante experimento u observación. A partir de alli, pueden identificarse diversos tipos de explicación - que aquí se denominarán explicandos como forma que adopta la explicación de un objeto o fenómeno-, a saber: el nomológico-deductivo, con subvariantes como el causal y el hipotéticodeductivo, el estadístico-inductivo, el conceptual, el genético, el funcional y el intencional, relativo a intenciones, disposiciones, motivos y razones. (7)

En los discursos de las ciencias sociales - esto es, en una serie articulada de enunciados tendientes a establecer los cómo, qué y por qué del objeto o fenómeno relativo al mundo social- se utilizan variados explicandos. Para dar cuenta de los hechos histórico-sociales en perspectiva diacrónica, el explicando debe referir a una pauta o serie de pautas y no a eventos imprevistos, ${ }^{(8)}$ pero de ello no se sigue que en el discurso de las ciencias sociales - o en el historiográfico en particularsea válido un solo tipo de explicando. Los diversos explicandos refieren a distintas formas de reconstrucción del continuo histórico que pueden ser combinados en el discurso genético/narrativo propio de la historiografia. En su tipologia de explicandos, Schuster destaca el carácter específicamente histórico de las explicaciones genéticas, y debe aceptarse que el modo de argumentación propio de la historiografía implica como norma general esa forma de explicación. (9) Pero puede argüirse 
que las explicaciones genéticas no constituirían de por sí un explicando autosuficiente, sino que se servirian de otros diversos explicandos para establecer razones de acontecimientos en una cadena temporal.

Como explicandos básicos del modo de discurso historiográfico, articulados con la explicación genética, pueden señalarse: a) la explicación causal, que se apoya en la detección de las causas de un hecho histórico, principalmente bajo la forma hipotético-deductiva y que - como lo ha destacado MacIntyre- ${ }^{(10)}$ refiere fundamentalmente a la causalidad entendida como relación singular con escasa tendencia a las explicaciones legaliformes, b) la explicación intencional, que se basa en el análisis de un hecho histórico de acuerdo a sus consecuencias intencionales vistos los propósitos y acciones de determinados actores, y c) la explicación funcional, que intenta dar cuenta de los hechos históricos en términos de consecuencias reales. Otros explicandos son utilizados en la historiografia con más escasa asiduidad y principalmente con fines clarificatorios o ilustrativos, como ser las explicaciones conceptuales. Asimismo, si bien las explicaciones estadístico-inductivas son ampliamente utilizadas por cierta historiografia - v.g. la ya antigua historia serial o cuantitativa-, son dominantes en ciencias sociales con un mayor grado de formalización, como la sociología y la economía.

Puede adelantarse que todos los explicandos requieren de cierto tipo de ejercicio de la valoración para su desarrollo, aun cuando ello no sea patente con relación al explicando nomológico-deductivo; el "modelo de explicación más riguroso y exigente" según Schuster. ${ }^{(11)}$ Esto tampoco quiere decir que no existan valoraciones en la derivación deductiva de relaciones entre fenómenos ni en los enunciados concretos sobre ellos, sino simplemente que la formulación de leyes o principios generales reduce el margen de asignación de valor correspondiente al momento de aplicación de esas leyes o principios a leyes de grado inferior o a acontecimientos singulares. Pero como en las ciencias sociales la formulación de leyes o principios generales - por otra parte de escasa frecuencia y aplicación- no reviste un carácter taxativo sino meramente indicativo, debiendo entenderse los enunciados generales más como manifestación de tendencias o constantes que como enunciados normativos, podemos hacer abstracción en esta oportunidad de las cuestiones relativas a ese explicando.

Asimismo, la discusión sobre el papel de los juicios de valor en la comprensión se encuentra en relación directa con respecto a la posibilidad de distinción entre ésta y la explicación. En Conocimiento objetivo Popper diferenció tajantemente la explicación de la comprensión, manifestando - a propósito de Dilthey y Collingwood- que "... la comprensión se basa en nucstra común humanidad. Se trata en su forma fundamental de un tipo de identificación intuitiva con los otros hombres, en la que nos vemos ayudados por movimientos expresivos, como gestos y palabras. Es además una comprensión de las acciones humanas. Y por último es una comprensión de los productos de la mente humana".(12) La idea de un "tipo de identificación intuitiva" de carácter psicológico desacredita en el paradigma positivista toda 
pretensión de cientificidad para aquellas disciplinas que utilizan la comprensión para dar cuenta del mundo social. Con esa separación se torna factible argumentar acerca de la atribución de valor en la comprensión, propia de disciplinas no científicas, y la asepsia valorativa de la explicación, relativa a las ciencias.

Fue desde luego Max Weber quien rompió con esa dicotomía absoluta entre explicación y comprensión en su proyecto de dar status científico a la sociología, una vez fracturado el paradigma fisiológico de esa disciplina desarrollado en el siglo XIX. ${ }^{(13)}$ A esos fines, entendió a la comprensión no como un procedimiento psicológico, sino como un método de conocimiento que implica la formación de hipótesis interpretativas sujetas a verificación. Luego, lo que la lógica del método impone es la necesidad de verificar empíricamente esas interpretaciones - mediante el recurso a la detección de uniformidades controlables-y traducirlas en una forma de explicación causal, que asume en Weber la forma de explicación condicional. De esta forma elevó la comprensión a modo de conocimiento científico, abriendo el camino para una hermenéutica rigurosa que no se encontrara fijada a la empatía o identificación con el objeto de conocimiento, sino que se articulara con procedimientos analíticos y con modos de razonamiento lógicos.

Weber también fue consciente de la importancia de la valoración con respecto a la comprensión de los fenómenos histórico-sociales y propuso el uso de una "interpretación valorativa". Sin embargo, preso en su propia "jaula de hierro" de la separación entre juicios de valor y saber positivo, no podía dedicar sus consideraciones a dilucidar el papel de las valoraciones en la comprensión. Además, su concepción de la comprensión siguió atada al modelo psicologista en tanto la refería a estados mentales subjetivos. ${ }^{(14)}$ Necesitamos entonces precisar de mejor manera los diferentes tipos de juicios que hacen al entendimiento de la experiencia y la vinculación entre juicios de valor y afirmaciones positivas, para fundar una mirada más crítica sobre la relación entre explicación y comprensión.

Jürgen Habermas, luego de diferenciar objetividad y verdad - o problema de la constitución del objeto y problema de validez- a partir de la distinción de Apel entre "constitución de sentido" y "reflexión de validez", destaca que los universos de la experiencia y la argumentación a los que refieren esos términos se hallan vinculados a través de las estructuras de la intersubjetividad lingūística. Y la comunicación lingüística posee una doble estructura ya que “... sólo es posible el entendimiento acerca de experiencias y contenidos proposicionales si simultáneamente tiene lugar una metacomunicación sobre la elección de una de las posibles relaciones interpersonales". Así, la estabilización reflexiva de intenciones recíprocamente expectables transforma las sensaciones, necesidades y sentimientos en constataciones, deseos y satisfacciones o padecimientos - sea con pretensión de objetividad, sea simplemente subjetivos-. Las percepciones de objetos de la experiencia se expresan como afirmaciones (juicios declarativos), los deseos pueden aspirar a expresar intereses generalizables justificados mediante normas de acción 
(juicios normativos) y las satisfacciones, en la medida en que sean objetivables, pueden ser justificadas a partir de criterios de valoración (juicios evaluativos). (15)

$\mathrm{La}$ distinción entre afirmaciones necesariamente objetivables - so pena de ser mera fantasía - por un lado, y normas y valoraciones que dependen del reconocimiento intersubjetivo, hace que estas últimas no se apoyen necesariamente en la circunstancia empírica del reconocimiento fáctico, sino "... en la resolubilidad discursiva de la pretensión de validez de las normas de acción y de los criterios de valor subyacentes en cada caso", y "dichas pretensiones de rectitud o de adecuación pueden ser comprobadas y razonadas o rechazadas en discursos prácticos", esto es, en una acción comunicativa en circunstancias determinadas. Para Habermas la diferenciación entre juicios declarativos por un lado, y normativos y evaluativos por el otro, "... no puede ser utilizada como objeción contra la unidad de la argumentación, ni como objeción contra la apertura del progreso teórico...".(16)

De esta forma, el desarrollo argumentativo implica una especial conjunción de operaciones explicativas y comprensivas orientadas por la teoría, en la cual los juicios declarativos, normativos y evaluativos se articulan entre sí y se validan por reconocimiento fáctico y por resolubilidad intersubjetiva. La comprensión del sentido depende de la construcción de una secuencia de manifestaciones y expresiones que superen la descripción, y en la cual son imprescindibles tanto las afirmaciones sobre lo observable derivadas de la experiencia sensorial como las afirmaciones relativas a la interpretación de las experiencias comunicativas. $\mathrm{La}$ comprensión es entonces una operación intelectiva directamente dependiente de una narración, es decir - acota Habermas-, de una historia.

En este sentido es que puede afirmarse la pertinencia de la "explicación narrativa", cuya formulación rompe la dicotomía positivista entre explicación y comprensión de una manera mucho más clara que la weberiana. Los diversos explicandos se conjugan con la formulación de hipótesis interpretativas en la unidad de la argumentación, lo que difumina a su vez la diferenciación entre un universo de discurso articulado por juicios declarativos y otro dominado por los juicios de valor. No se trata ya de "traducir" las hipótesis interpretativas a formas de explicación causal como hacía Max Weber, sino de aceptar que las operaciones explicativas implican procesos de Verstehen en el ámbito de una intersubjetividad lingüística. Con esto cerraríamos el abanico taxonómico que habíamos abierto antes - y que como toda tipología es sólo una premisa de la argumentación-, para concebir a la explicación narrativa como la forma discursiva propia de las ciencias sociales, que articula enunciados positivos y enunciados valorativos (normas y evaluaciones) mediante el recurso a diversos explicandos y a la formulación de hipótesis interpretativas; forma que es desde luego la propia del discurso historiográfico. La imposibilidad de eliminar en los discursos prácticos la apelación a normas de acción y criterios de valoración no viene dada solamente por el carácter socialmente situado de las prácticas científicas o por la atribución de valor a 
factores bajo análisis, sino también por la articulación de enunciados positivos e interpretaciones en la secuencia de los enunciados.

3.

A partir de la concepción habermasiana - y más allá de ella- podemos interrogarnos sobre una primera función de los juicios de valor con respecto a las explicaciones narrativas, en orden a la naturaleza lógica del juicio. Por una parte, los juicios declarativos no son solamente afirmaciones objetivables sino que también expresan una relación de acuerdo intersubjetivo con respecto a un referente. Por otra, los juicios de valor implican no sólo la resolubilidad discursiva de los criterios de valor sino también el establecimiento de una relación con un referente. Al establecer una conexión entre un sujeto y un predicado, todo juicio postula una condición de la existencia. Podemos afirmar entonces que torna pensable un contenido relativo a una materia determinada. "Los juicios de valor -dice Gardella-, además de expresar actitudes emotivo-volitivas pretenden constatar algo que tiene existencia objetiva, es decir independientemente del sujeto que los formula".(17) De esta manera, los juicios de valor expresan relaciones de acuerdo entre los sujetos con respecto al sentido de los acontecimientos y se transforman en portadores de conocimiento; implican la toma de posición de un sujeto determinado en un complejo de relaciones comunicativas con respecto a la interpretación de la experiencia (acontecimientos, actos determinados en una situación dada) y con respecto a la interpretación de ciertas regularidades (un tipo determinado de acontecimientos o actos con independencia de las situaciones experienciales concretas). En el proceso de producción de conocimiento sobre lo social, los juicios declarativos y los juicios de valor cumplen una misma función de acuerdo intersubjetivo sobre la experiencia, y por tanto establecen una relación con un referente objetivable.

Esa situación se relaciona con la posibilidad o no de postular una dicotomía entre hechos y valores. El mismo Weber percibió la "dificultad" de distinguir claramente en el discurso entre afirmaciones (o juicios declarativos) y valoraciones (o juicios de valor). "No quisiera discutir además - admitió- si la distinción entre comprobación empírica y valoración práctica es difícil de trazar. Por cierto que lo es". La irresolución del problema que suscitaba para su teoría la permanente presencia del valor queda patente en su postulación de la "interpretación valorativa" como método comprensivo, a propósito de la historia del arte: "Ha de admitirse... - escribía-, que quien desea obtener resultados en materia de historia del arte, por más empírica que sea, necesita poder 'comprender' la producción artística, lo cual es impensable, por cierto, sin una capacidad de juzgar estética y, por lo tanto, sin la capacidad de valoración. Lo mismo vale, como es natural, para el historiador de la política o de la literatura, de la religión o de la filosofia. Pero ello no significa absolutamente nada para la esencia lógica de la labor histórica" (18) La 
contradicción inmanente en Weber entre el método comprensivo y el método científico axiológicamente neutro propio del paradigma nomológico-deductivo es evidente en el párrafo citado, teniendo especialmente en cuenta la frase que lo cierra. Si el hecho histórico se construye a partir de métodos, hipótesis y técnicas de investigación, serán criterios de valor los que le den entidad. En el seno de la operación histórica, la capacidad de comprensión no es escindible de la identificación positiva; construir un hecho o concepto es ya comprenderlo de una determinada manera.

Por lo demás, la imposibilidad de prescindir de oraciones que expresen criterios de valoración en los discursos científicos no afecta sólo a disciplinas como la historia - que algunos verían cercana a la estética-, sino a las mismas ciencias formales y naturales. Mario Bunge destaca que: "No puede prescindirse de ellas al nivel pragmático porque en toda acción reflexiva... se dan relaciones de fines a medios. Y no podemos prescindir de los juicios de valor al nivel metacientífico porque a este nivel comparamos entre sí procedimientos y teorías, y damos normas a las que deseamos que se ajusten los objetos comparados".(19) Quizás el problema de la asignación de valor en el conocimiento científico no es estrictamente una cuestión de lenguaje, como postula Bunge, sino mejor de discurso. Esto es, tendría que ver con efectos discursivos concretos y con atribuciones de significado en la relación entre signos y referente, más que con la significación como tal. ${ }^{(20)}$ Pero sea como fuere la solución no se encontraría en negar la asignación de valor, sino en asentarla en razones fundadas, explicándola y justificándola argumentativamente de la misma manera en la cual nos vemos obligados a fundamentar los juicios declarativos.

En una segunda dimensión los juicios de valor aparecen como la premisa de toda explicación, por cuanto fundamentan la elección de un tema de estudio. Para dar respuesta a esa situación que ponía en entredicho su concepto de objetividad develando el ejercicio de la valoración, Max Weber retomó la distinción de Rickert entre "juicio de valor" y "relación de valor". Las ciencias histórico-sociales no admitirían ninguna valoración práctica, pero sí establecerian una relación puramente teórica con los valores que delimitan su objeto dentro de la multiplicidad de datos empíricos. La "relación de valor" no sería un juicio de valor en tanto que no importaría un principio de valor, sino un principio de selección previo a la labor científica en orden a la "significación cultural" del objeto. Los valores actuarian así como un "criterio de selección", organizando la base de las ciencias sociales desde lo subjetivo (la selección del objeto) a lo objetivo (la investigación sobre el objeto y

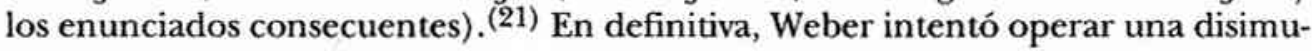
lación del valor mediante el mecanismo de suponerlo previo al procedimiento científico lo que, unido a la prohibición formal de fundar científicamente juicios de valor, pone a la teoría y a la investigación empírica bajo la dependencia de la "subjetividad individual" o a lo sumo de la "significación cultural" sin otorgarles la posibilidad de influir sobre los valores. Construyó así, en términos práctico-políti- 
cos, un camino del ciudadano (o mejor, del individuo) al cientista social que no puede reconocer regreso so pena de transgredir la supuesta "neutralidad valorativa".

Demás está decir que la solución de compromiso de Weber manifiesta falencias. No sólo se apoya en un objetivismo propio de la ciencia social decimonónica puesto repetidamente en cuestión por diversas corrientes teóricas y en una consecuente distinción hecho/valor discutible, sino que sobre todo debe observarse que la adopción de valores como criterios rectores de la investigación implica ya una toma de posición. En tanto que formalmente constituye un procedimiento de asignación de valor, la "relación de valor" es ya un juicio de valor que jerarquiza el mundo de la experiencia. La determinación de un tema por intereses de valor para demostrar científicamente las "chances o consecuencias prácticas" de una acción social determinada, no es más axiológicamente neutra que un enunciado valorativo sobre esa acción social. El cientista social weberiano puede abstenerse de realizar juicios de valor porque en realidad ya los ha realizado apriorísticamente. (22) Puede postularse que la apelación a asignaciones de valor iniciales orienta las determinaciones conceptuales y procedimentales, el proceso de explicación/comprensión en su generalidad y los mismos resultados del trabajo disciplinar. El juicio de valor actúa así como premisa general que guía la determinación de consecuencias, y en tal sentido se encontraría también sujeto a las críticas de adecuación lógica y empírica - por lo cual, pace Weber, existiría también un camino de retorno del cientista social al ciudadano-.

Debemos colegir entonces que tanto en el desarrollo de las explicaciones narrativas como en el establecimiento de las premisas de toda explicación, nos encontramos en las ciencias histórico-sociales con problemas relativos a la asignación de valor y a la consecuente emisión - explícita o implícita- de juicios de valor. ${ }^{(23)}$ Asimismo el recurso a explicaciones narrativas en la historiografia, en las cuales se combinan explicandos y formas de interpretación para dar cuenta de un desarrollo particular en el espacio-tiempo, importa valoraciones más complejas que las derivadas del desarrollo de los diversos explicandos por separado, aun cuando es patente que en cada uno de ellos nos encontramos con operaciones de asignación de valor en - por ejemplo- la determinación de órdenes causales, indagación sobre intenciones o configuración de redes funcionales.

Se puede observar que el concepto de proceso propio de las reconstrucciones explicativas y de las narraciones en general, implica la noción de un direccionamiento - no prefijado en su desarrollo real, sino postulado en el orden del discurso a los fines de una mejor explicación-. Así, la representación de un proceso diacrónico implica la atribución de valor a elementos o factores propios, ajenos y posteriores a él, construyendo una explicación y destacando rupturas o continuidades en base a criterios de valor. Esto es patente sobre todo en aquella historiografia que defiende la noción de procesos históricos, ${ }^{(24)}$ pero se encuentra igualmente latente en todas aquellas narraciones que aun siendo impresionistas y fragmenta- 
rias - con lo que no constituyen en rigor explicaciones narrativas- intentan dar cuenta de diferencias, discontinuidades o estados particulares.

Las explicaciones narrativas implican también habitualmente el recurso a hipótesis alternativas, o en términos más concretos, a simulaciones históricas. La simulación histórica puede ser planteada como imaginación acerca de cómo habría evolucionado una situación de haber variado ciertas condiciones, o como imaginación acerca de cómo se desarrolló un proceso acerca del cual no disponemos de información suficiente. Tanto en uno como en otro caso el recurso al juicio de valor por la vía de los explicandos o por la vía de la opción imaginativa son evidentes.

Otra dimensión del problema del valor en la explicación narrativa es la referente al papel de los juicios en la verificación de las explicaciones que se hubieran formulado con anterioridad con respecto a un fenómeno. Esta dimensión forma parte del proceso de producción del conocimiento histórico, si admitimos que en la labor del historiador la crítica de documentos no es escindible de la crítica de la historiografia. En términos de Alain Guerreau, una aproximación racional a las realidades sociales pretéritas implica la clarificación de tres órdenes de relaciones posibles: 1) las representaciones que una sociedad pretérita se hacía de sí misma, 2) las representaciones actuales de nuestra propia sociedad, y 3) las representaciones actuales proyectadas sobre las sociedades pretéritas. ${ }^{(25)}$ Desde esa perspectiva, la crítica de los valores subyacentes a las explicaciones historiográficas preexistentes es una parte del proceso de producción del conocimiento histórico. El ejercicio de la crítica se realiza aquí como puesta en cuestión de los modelos explicativos a partir del develamiento de los valores que presupone su desarrollo. La crítica de valores subyacentes opera de forma complementaria con las dos formas fundamentales de la crítica de explicaciones: la crítica de la lógica interna y la crítica de adecuación empírica, y - como se ha visto- criticar una asignación de valor es siempre proponer una evaluación propia.

\section{4.}

De esta forma, el desarrollo argumentativo implica una especial conjunción de operaciones explicativas y comprensivas orientadas por la teoría, en la cual los juicios declarativos, normativos y evaluativos se articulan entre sí y se validan por reconocimiento fáctico y por resolubilidad intersubjetiva. Como también se ha postulado, el juicio de valor cumple variadas funciones en las explicaciones narrativas y resulta consustancial a las operaciones del discurso historiográfico. Pero aun aceptando tales premisas cabe preguntarse si no existe una limitación cultural a la enunciación de juicios de valor, dada por la relatividad cultural de los valores. Concretamente: ¿son posibles los juicios de valor interculturales o las otras culturas son tan opacas a nuestra indagación que resultarían faltos de toda sustentación? La cuestión es de principal importancia no sólo para el conjunto de las ciencias 
sociales y sino en particular para la historia, porque en rigor toda cultura pretérita es "otra cultura".

La versión académica posmoderna del pensamiento fragmentario entronizó en la década de 1980 el relativismo cultural, con la consiguiente impugnación de los juicios de valor interculturales. Como lo destaca Riccardo Scartezzini, ${ }^{(26)}$ la relación entre relativismo y universalismo teóricos y prácticos no es lineal y transparente, sino sumamente compleja y entrecruzada, de manera tal que no podemos construir sin más un espantajo "relativista" para luego proceder a su crítica. Con todo, las posiciones relativistas implican generalmente una concepción de mayor o menor inconmensurabilidad cultural y la consiguiente imposibilidad de emitir juicios válidos con respecto a otras culturas - e incluso, en el extremo, de llegar a comprender realmente algo de dichas culturas como no sea sumergiéndonos en ellas-. Es por ello que el relativismo lleva de una u otra forma al postulado último de que la imagen que de una sociedad o de sus aspectos particulares tienen los propios actores es la más ajustada posible, dado que las categorías lingūísticas mediante las cuales se construye la experiencia cultural no pueden ser plenamente captadas por los actores inmersos en otras culturas.

En ese sentido, amplios sectores de la historiografia acusaron el fuerte impacto de las concepciones planteadas en las décadas de 1950-60 por Peter Winch y, posteriormente y con variaciones de importancia, por Clifford Geertz. En esta tradición uno de los postulados más fuertes en favor de la inconmensurabilidad cultural es el de la estrecha relación entre lenguaje y experiencia, e incluso de la constitución de la realidad a través de las categorias del lenguaje. En términos de Wittgenstein, cuya recuperación opera Winch, los límites de nuestro lenguaje son los límites de nuestro mundo, por lo que no resultaría pertinente la aplicación de nuestros juegos lingūísticos a la comprensión de otras culturas. $\mathrm{Y}$ en rigor, la realidad objetiva no podría concebirse como exterior al lenguaje y la cultura. ${ }^{(27)} \mathrm{El}$ lenguaje aparece como instituyente de la experiencia inmediata, al punto de registrar átomos de representación (un concepto-una cosa) y postular en ocasiones el acceso directo a lo empírico por medio de las categorias del lenguaje corriente. La falta de distinción entre el saber mutuo de investigadores y legos de las creencias del sentido común, ${ }^{(28)}$ conduce al callejón hermenéutico de la "fusión de horizontes". Por otra parte, el acceso a la alteridad por conducto de textos que son interpretados a partir de su unicidad conlleva un proceso circular en el cual los criterios de verdad y relevancia se tornan arbitrarios y quedan encerrados en una hermenéutica constitutiva. (29) La experiencia cultural es entendida como una alteridad irreductible, que sólo puede ser captada plenamente por los hablantes que participan del mismo juego y que se plasma al momento del análisis histórico o antropológico en una relación identitaria entre texto y contexto. Adicionalmente, esa relación tiende a presentarse en un marco de inmovilismo de los sistemas de creencias, que hace que los procesos históricos de transición entre diversas configuraciones sólo puedan ser captados como "saltos gestálticos".(30) 
El problema planteado por el relativismo nos remite a la discusión de una concepción de verdad que refiera a la triple dimensión del mundo de los objetos, el mundo social y la misma interioridad del sujeto. La posibilidad de que un enunciado de cualquier tipo se constituya como verdad, como portador de conocimiento verdadero, no depende meramente del uso de tales o cuales conceptos y del acuerdo intersubjetivo, sino también - y sobre todo- de que se encuentre en una relación de coherencia lógica con otros enunciados en el discurso - esto es, que no sea contradictorio-, de que esa relación no sea tautológica — es decir, que no sea circular- y de que no puedan fundarse empíricamente enunciados que le sean contradictorios -o sea, que resista la falsación-. La comprobación empírica, no ya bajo la ilusoria intención de agotar la experiencia sino bajo la forma de la falsación, se constituye entonces en un reaseguro de la verdad de las afirmaciones positivas y los juicios de valor, con lo cual es posible someter los juicios de valor interculturales a la apelación a un algo exterior a las categorías del lenguaje y al acuerdo de los sujetos - aun cuando, claro está, estas son las vías ineludibles de esa apelación-. Es cierto que "Cualquier lengua... es una conspiración contra la experiencia en el sentido de que es un intento colectivo de simplificarla y ordenarla en parcelas manejables",(31) pero de ello no se sigue que la experiencia y su entendimiento se encuentren absolutamente presos del lenguaje $-\mathrm{y}$ a más, del lenguaje común-. Salvo apelación a un idealismo absoluto, debemos conceder que existe algo exterior a los sujetos cognoscentes con lo cual se puede cotejar la experiencia, y ese algo no depende necesariamente para su existencia del universo del lenguaje. Por lo tanto, existe una realidad exterior a los sujetos - y construida también por ellos en términos de interacción- que es una cosa distinta de la conciencia y las categorías lingũísticas de los sujetos, con lo cual no podemos - parafraseando a Marx - juzgar la experiencia de determinados actores por la conciencia que ellos manifiestan sobre dicha experiencia, es decir, por su relación imaginaria con el mundo.

I. C. Jarvie ha presentado una interesante afirmación de la pertinencia de los juicios de valor interculturales y de defensa de un concepto de verdad científica frente al relativismo cultural, al objetar los planteos de Peter Winch. (32) Para Jarvie, objetivista convencido, la constricción institucional impide un conocimiento del mundo ajustado a la realidad objetiva en todas las sociedades - y aquí se entienden las instituciones como complejos de roles-, pero la tradición científica nacida en las sociedades "occidentales" aporta medios para el logro de enunciados verdaderos. Y todavía cuando convengamos en que utiliza un concepto "duro" de verdad, la contundencia de su argumentación es dificilmente rechazable: por más que la experiencia sensible nos diga que "el Sol sale y se pone" y que diversas culturas tengan multitud de maneras de referir a esa experiencia, no estaríamos dispuestos a reconocer validez a tal afirmación frente a una argumentación científica sobre la mecánica celeste. De alli se puede colegir que mediante procedimientos determinados podemos lograr una percepción de la realidad objetiva no sólo natural sino 
también social, que se compadezca mejor con ese exterior al sujeto. El problema se presenta al tratar de emitir juicios con respecto a otras culturas - aunque quizás fuera mejor decir: con respecto a otras formas de dotación de sentido- estableciendo el valor de verdad de diversos aspectos. Aun manifestando una decidida oposición a la antropologia intelectualista que entiende a la propia sociedad como modelo positivo de comprensibilidad, Jarvie postula que puede utilizarse esa propia sociedad como instrumento de medida o tabla de corrección para desarrollar juegos lingūísticos en los cuales los juicios de valor interculturales constituyan jugadas legítimas que permitan alcanzar la comprensión de la sociedad ajena.

Jarvie apunta correctamente que "...si los criterios evaluativos de sociedades diferentes fueran inconmensurables, no existiría, y no podría existir, una ciencia social, ni siquiera la historia. Después de todo, la historia es el intento de explicar el pasado en términos del presente..". La comprensión aparece así como un proceso de dotación de sentido a partir de preconcepciones que se encuentran a su vez sometidas a corrección. La actividad de la ciencia social puede concebirse como un proceso en el que se llevan ideas, criterios y concepciones de nuestra cultura sobre los de otras culturas, en una relación interactiva que permite modificar nuestros propios conceptos y correspondencias, en otros términos - en lo que Jarvie sigue a Gellner-, como un proceso de traducción sujeto a corrección: “...no podemos más que intentar traducir las sociedades que nos son extrañas en términos de la nuestra, y... únicamente allí donde aparecen lagunas e inconsistencias en nuestra traducción examinamos nuestras preconcepciones y las cambiamos".(33)

La cuestión tratada en la polémica entre Winch y Jarvie guarda intensa actualidad y al mismo tiempo podría decirse que ya resulta remanida. La desconfianza posmoderna en las concepciones ilustradas de razón, verdad y objetividad potenció el relativismo desde fines de los años setenta y en los ochenta, con el curioso resultado de suplantar un reduccionismo (el del lenguaje al objeto) por otro (el del objeto al lenguaje). En los términos del posmodernismo más acérrimo, no podríamos emitir juicios de valor interculturales porque para comparar dos grupos de valores deberiamos suponer una tercera clase de racionalidad en la cual ambos estuvieran abarcados, lo que en realidad — señala Terry Eagleton- es “...una falaz presunción a posteriori; [ya que] no es por virtud de un tercer lenguaje compartido que podemos traducir del inglés al malayo". ${ }^{(34)}$ Como el mismo autor destaca, las implicancias políticas conservadoras de una tal posición no son pocas: el multiculturalismo y la noción de un orden poscolonial terminan por autenticar lo existente y negar la posibilidad de toda discusión racional sobre valores.

La concepción traductiva de la labor científica no desconoce la diferencia cultural. Se sabe que todo traductor "re-escribe" la obra original y que no podemos postular una relación identitaria entre el ser y el decir: nuestras concepciones - aun resguardadas por los métodos científicos- son sólo representaciones de esa siempre esquiv ‘ "realidad objetiva". Se puede admitir también que inconmensurabilidad, traductibilidad y conmensurabilidad no son dimensiones con relaciones 
simples, ${ }^{(35)}$ y sobre todo que la asunción de la posibilidad de la segunda no asegura la afirmación de la tercera. El mismo Jarvie abandona su objetivismo para destacar que “...todos nuestros esfuerzos por entender serán malentendidos, juicios erróneos y simplificaciones injustificadas. Todo lo que podemos hacer al respecto es hacer frente a este hecho y ser lo más críticos que podamos con nuestros esfuerzos". (36) Esos juicios aproximativos constantemente sometidos a la autorreflexión constituyen la única salida legítima para un pensamiento científico que no caiga en el objetivismo ingenuo pero que tampoco renuncie a sus propios presupuestos lógicos y a los procedimientos racionales que constituyen su base.

\section{5.}

No es infrecuente la asunción de la asignación de valor en la producción historiográfica, y muchos historiadores de oficio clarifican sus propias posiciones entendiendo que se trata de una interpelación política en un campo intelectual determinado. Lo que interesa particularmente es dilucidar una estrecha vinculación entre el desarrollo de los conocimientos científicos y el reconocimiento de normas y valores, para lo cual resulta conveniente asomarnos a un ejemplo de discurso historiográfico para tratar de ilustrar cómo se conjugan esas dos dimensiones de las ciencias histórico-sociales: la epistemológica y la práctico-política.

$\mathrm{Si}$ bien casos como el de Edward $\mathrm{P}$. Thompson pueden resultar al respecto paradigmáticos, al encontrarnos frente a una relación expresa entre teoría, historia y política que recurre a los valores como elementos que nos permiten comprender una situación de vida determinada, puede ser conveniente acercarse brevemente a un texto particular de un historiador que no ha manifestado una posición política tan clara como la de Thompson y cuyo método de investigación no recurre a la identificación empática. Para ello es útil revisar una compilación de artículos de Pierre Bonnassie titulada Del esclavismo al feudalismo en Europa occidental, que reúne artículos y ponencias escritos entre los años 1980 y 1990, continuando la línea de análisis presentada por este medievalista en La Catalogne du milieu du Xe. à la fin du XIe. siècle: croissance et mutations dune société. ${ }^{(37)}$ Los primeros avances de la investigación que luego plasmaría en los diversos artículos reunidos en la citada compilación fueron realizados por Bonnassie a fines de la década de 1970 e inicios de la de 1980. En ese marco temporal este autor establece una relación dialógica con Pierre Dockés, economista político que en su libro La liberación medieval se sirvió de los primeros trabajos de Bonnassie y que luego sería asiduamente citado - tanto crítica como elogiosamente- por éste. ${ }^{(38)}$

Interesa particularmente el ejemplo traido a comentario por cuanto puede aventurarse que Bonnassie desarrolla un modo de argumentación articulado en torno al juicio de valor. Así, el análisis de la incidencia de la lucha de clases en el proceso de desaparición de la esclavitud antigua se realiza a partir de la expresa 
enunciación de un juicio evaluativo sobre la misma: “...el régimen esclavista es un sistema de opresión especialmente cruel y degradante al que los hombres y mujeres sólo pueden estar sometidos y en el que sólo pueden ser mantenidos por la fuerza".(39) Esta concepción, radicalmente crítica y opuesta a la descripción "neutra" de un estado de cosas, permite inferir una relación directa entre el desarrollo del esclavismo y el de los aparatos de Estado, y a la inversa, entre su mutua desarticulación: "La presión ejercida por los esclavos por liberarse, por acceder a la dignidad humana, es constante, y sólo se puede contener con un aparato represivo eficaz, es decir, un aparato de Estado. Por ello, podemos suponer que todo período de debilitamiento de las estructuras estatales se caracteriza por luchas serviles. Unas luchas cuyas manifestaciones pueden variar según las circunstancias: una veces rebelión abierta, y otras - lo más corriente- desobediencia soterrada, insumisión latente.".(pág. 62) En su construcción de una explicación narrativa sobre la supervivencia y extinción del régimen esclavista en la Alta Edad Media,(págs. 13-75) Bonnassie intenta presentar variadas explicaciones causales y funcionales, en una forma de exposición que destaca la "multicausalidad" y recurre a sustentos teóricos que abrevan principal pero no únicamente en la antropología y en el materialismo histórico. Con todo, es también notorio que termina por concebir a la liberación parcial que implica la desestructuración de la esclavitud como una conquista, que culmina hacia el año mil con una "impugnación general de la propia noción de servidumbre por parte de los esclavos".(pág. 66)

Asimismo, el juicio de valor sobre la libertad y la servidumbre es traído a colación para la clarificación de las fuentes del crecimiento económico de la Alta Edad Media. La lucha por la supervivencia es puesta en el mismo plano que las esperanzas de liberación para explicar las motivaciones del proceso de rozamientos. La explicación narrativa de Bonnassie se desarrolla mediante la conjugación de un explicando causal que detecta los elementos que produjeron el crecimiento agrícola de la Europa occidental-mediterránea en los siglos IX-X, un explicando funcional que da cuenta de las modalidades de las estructuras agrarias y una comprensión de razones - que podrían fundar un explicando intencional一, todo ello en una perspectiva cronológica. Es de hacer notar que los fundamentos del proceso de crecimiento agrícola son esclarecidos mediante la discusión sobre los motivos de los campesinos roturadores, bajo el supuesto de una concepción negativa de la servidumbre que explica la búsqueda de mayor independencia por las jóvenes parejas o familias de tipo conyugal. (págs. 105-135 y especialmente 112-114)

La detección de nudos textuales relativos al problema que nos ocupa podría seguir con similares resultados. Mayormente, el juicio de valor actúa como premisa de la que se extraen consecuencias en términos de explicaciones causales, funcionales o intencionales. Prácticamente cada artículo de Bonnassie apela a juicios de valor explícitos para clarificar los distintos temas, (así, cf. especialmente págs. 104, 164 y 291) pero que de ninguna manera son sustraídos a la reflexión racional como aportes subjetivos de una etapa previa a la investigación. Al apoyar sus razonamien- 
tos en una firme base documental que permite convalidar su argumentación, puede pretender una confirmación del juicio. La revisión sistemática del corpus documental disponible, el sustento de investigaciones regionales y el uso de un método comparativo son los pilares de una operación historiográfica, en la que se intenta comprender la pervivencia y mutación de formas sociales criticando los criterios de valor que esas formas suponen. Es posible aducir que Bonnassie crea un "efecto de realidad" y que su discurso es evidentemente persuasivo, pero no por ello puede negarse que intenta cumplir con una adecuación teórica y empírica.

El proceso de explicación/comprensión trata en todo momento de destacar la común humanidad que nos une con los campesinos de los siglos medievales, más allá de la alteridad cultural. De esa manera la comprensión histórica se logra a partir de la preocupación por los derechos humanos concebidos como valores universales: "...la igualdad de los cuerpos ante el sufrimiento... es la prueba de que no hay infrahombres, y de que la esclavización del hombre por el hombre es inaceptable". (pág. 291) Lejos de la noción de que toda sociedad sigue una serie de "reglas" o que se halla presa de "juegos de lenguaje", lejos de someterse al imperativo de "comprender una época en sí misma", Bonnassie percibe que se puede acceder a la clarificación de las motivaciones, las acciones y los sufrimientos mediante un trabajo traductivo de explicación y comprensión de esa otra cultura. $Y$ entonces un asesinato es un asesinato, la explotación es la explotación, y no formas culturales ajenas a la evaluación de quienes no se encuentran inmersos en ellas.

Cobra aquí sentido la adhesión de Bonnassie a la tradición de Marc Bloch, ${ }^{(40)}$ así como su firme actitud contra los historiadores actuales que no manifiestan preocupación por valores universales: "El número de golpes que puede recibir un esclavo, ateniéndonos a las leyes, es espantoso: decenas, cientos de golpes, tantos o más que un buey o un perro. ¿Qué clase de golpes? Una vez más topamos con el silencio de los historiadores que se apasionan por los problemas institucionales más sutiles, pero al parecer se desinteresan por la forma en que eran golpeados sus antepasados". (pág. 33) Este cuestionamiento nos remite al sentido del conocimiento sobre lo social y a la indagación sobre nuestra propia práctica académica. $\mathrm{El}$ intento de Bonnassie por dilucidar temas casi desaparecidos de la agenda de la nueva ortodoxia, como la dominación de clase, el hambre o la explotación, entendidos no como manifestaciones textuales sino como situaciones experienciales concretas de seres humanos que nos precedieron, habla ya a las claras del criterio de valor que ha regido su investigación.

6.

La discusión disciplinar en las ciencias sociales y en la historia no puede evadirse de una doble tensión que la atraviesa: por un lado desde la epistemología debe dirimirse la cuestión sobre la pertinencia y factibilidad de los juicios de valor, pero 
desde la perspectiva de una dimensión práctico-política la cuestión refiere ya a la delimitación de los valores sobre los que se fundarán esos juicios y a su plasmación en explicaciones narrativas concretas. Es en este sentido que la discusión sobre la posibilidad lógica de la crítica de valores se transforma en discusión sobre la posibilidad práctica de construcción colectiva de valores. Cuál es el contenido sustantivo de esos valores y sus formas concretas de realización es la materia de discusión en esa dimensión práctico-política de las ciencias histórico-sociales. Éstas, como discursos socialmente posicionados, se encuentran en una situación de tensión que las configura como "...instrumento potencial para expandir la autonomia racional de la acción, pero igualmente como un instrumento de dominación potencial', en correspondencia con una tradición decimonónica que nació con la contraposición de las versiones de la sociología formuladas por Saint Simon y De Bonald - una "ciencia de oposición" contra una "ciencia de estabilización"-, y que encuentra su correlato actual en ciencias sociales "críticas" y "conservadoras". (41)

La construcción de las identidades sociales e individuales implica una orientación en determinados espacios morales, asignando grados de importancia al mundo de la experiencia y conformando imperativos o conveniencias de acción. La asunción explícita e implícita de valores es entonces inevitable porque, en palabras de Eagleton "Todo el mundo suscribe a alguna jerarquía de valores, un compromiso que es comprobadamente constitutivo del yo". (42) Desde un punto de vista crítico se trata de no asumir como dado un universo de valores, sino de someterlo constantemente a examen. El conocimiento crítico se guía por cómo las cosas podrían ser para criticar las cosas como son; inclusive - como se ha dicho- para ser crítico con respecto a sí mismo, a sus propias prácticas y a las representaciones de sus propios voceros. El conocimiento histórico crítico consiste entonces en la puesta en cuestión de los registros y de las configuraciones normativas y valorativas pasadas, en función de un conocer crítico de la propia experiencia.

$\mathrm{Si}$ los valores de justicia, libertad y autodeterminación, igualdad o -en un sentido general- derechos humanos, no constituyen entelequias suprahistóricas o formas ideales a las cuales conformar forzosamente la realidad, sino acuerdos intersubjetivos sobre aquello que entendemos válido para todos los seres humanos en cuanto tales, podemos acordar que en su asunción como criterios de valor se encontrará la posibilidad de un conocer crítico. El "instrumento de medida" para la postulación del valor de verdad de las sociedades pretéritas y de nuestra propia sociedad mundializada sería una "sociedad ideal", una utopia, y la crítica de lo existente se realizará conforme a los valores que el sujeto cognoscente entiende deben ser concretados. En este punto se aprecia la importancia de desenmascarar la propia relación imaginaria con el mundo -es decir, la propia ideología- y dilucidar los valores postulados desarrollando una imaginación proactiva - es decir, la utopía-. La exploración de las alternativas, de los espacios inexistentes, de los valores posibles, suministra los instrumentos intelectuales para la puesta en cuestión de lo devenido, de lo espacialmente situado, de los valores inmanentes. 
La concepción utopista permite postular valores que de ningún modo pueden entenderse como "superiores", pero sí debemos reconocer que algunos valores son mejores que otros en función de aquello que consideramos constitutivo de la humanidad, cual es la posibilidad de autodeterminación. Si la característica común a los seres humanos es que "...son determinados precisamente de una manera que les permite un grado de autodeterminación...",(43) todo valor que sustente la apertura del sujeto individual o colectivo hacia la autonomía puede convertirse en un valor universal. Y la defensa de la propia autodeterminación de las culturas frente a los discursos supremacistas, imperialistas y racistas no puede servir de pretexto "...para dimitir ante la defensa de valores que fueron creados por nosotros, que consideramos válidos para todos, que no tienen relación con la raza o el color de la piel y a los que queremos convertir, si, razonablemente, a toda la humani-

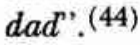

Sabiendo que estos valores no son "valores por sí" o representaciones de algún Bien supremo, sino parte esencial de un proyecto práctico-político, seremos capaces de comprenderlos como "... el objeto de una construcción... que, lejos de la filantropía espectacular, comprometa en primer lugar y antes que a la víctima, a aquel que se alza en defensor".(45) Esto es lo que la ácida denuncia de Pierre Bonnassie sobre los silencios de la corporación de los historiadores viene a poner al descubierto. La mirada valorativa sobre el pasado no se limita a la denuncia de la victimización, sino que implica una transformación cualitativa del denunciante en una relación dialéctica con la víctima: decir que eso nos importa es decir que no somos los mismos, que asumimos una posición, un cambio, un proyecto, y que por tanto nos conocemos por ese medio a nosotros mismos. El juicio de valor cumplirá entonces otra función en el proceso de producción de conocimiento que se expresa en las explicaciones narrativas de la historiografia; pero no ya para el conocimiento de esas otras culturas desaparecidas sino de nuestra misma cultura. Su manifestación reflexiva será un acto de autoconocimiento crítico.

\section{Notas}

(1) Jürgen Habermas, Teoria y praxis. Estudios de filosofia social, Madrid, Tecnos, 1990, págs. 297-298.

(2) Max Weber, Ensayos sobre melodología sociológica, Buenos Aires, Amorrortu, 1982, pág. 222, destacado en el original.

(3) Perry Anderson ha observado que el relativismo de Aron se mezcla con una visión esencialista de la especie humana, lo que lo distinguiría de sus epígonos empeñados en no admitir la procedencia de universal alguno. Perry Anderson, Los fines de la historia, Barcelona, Anagrama, 1997, pág. 64.

(4) Cf. José Sazbón, "La 'nueva' filosofia de la historia. Una sinopsis", en Prismas. Revista de Historia Intelectual, N², Buenos Aires, UNQ 1998.

(5) Definición de Thompson que, aunque limitada por cuanto pueden postularse funcionalidades integrativas e identificativas de la ideología, se entiende adecuada a los fines de dejar en claro la 
funcionalidad que una teoría crítica trata de develar en primer término. John B. Thompson, "Lenguaje e ideologia", en: Zona Abierta, N 41/42, Madrid, 1986-97, págs. 162 y ss.

(6) "La crítica no sólo rechaza juicios de valor o complejos de juicios de valor, sino también propone alternativas a lo rechazado. Dicho de otra manera: no sólo rechaza los juicios de valor que son, sino tambiên propone los juicios de valor que deben ser", Juan Carlos Gardella, "Supuestos epistemológicos de una Teoría Crítica", en: Papeles de Trabajo, $\mathrm{N}^{2}$ 2, Rosario, Centro de Estudios Interdisciplinarios en Etnolingüistica y Antropologia Socio-Cultural, UNR, 1992, pág. 42.

(7) Félix Gustavo Schuster, Explicación y predicción, Buenos Aires, CLACSO, 1992, págs. 21-29.

(8) Con la expresión "eventos imprevistos" se alude a acontecimientos extraídos de su marco de referencia, dejando de lado el (falso) problema del "azar" en el devenir social. En cierto sentido, todo es azaroso por cuanto "hubiera podido suceder de otra manera", o nada es azaroso por cuanto "nada sucede porque si". Siguiendo a Antoine-Augustin Cournot, puede plantearse que todo evento casual se produce por el encuentro de dos series causales diferentes (Anderson, op. cit. nota 3, págs. 34 y ss.), con lo que el análisis de un acontecimiento azaroso puede remitirse a explicaciones concurrentes.

(9) Félix Gustavo Schuster, op. cit. nota 7, pág. 26. Obsérvese al pasar que las formas fragmentarias del discurso historiográfico posmoderno que no construyen dimensiones diacrónicas bajo la noción de "proceso" (y sus contrapartes y concomitantes) no conscituyen en rigor "explicaciones", sino meras descripciones impresionistas.

(10) Alasdair MacIntyre, "Causalidad e historia", en: Juha Manninen y Ramo Tuomela (comps.), Enscyos solre explicación y comprensión. Contribuciones a la filosofía de las ciencias humanas y sociales, Madrid, Alianza, 1980.

(11) Félix Gustavo Schuster, op. cit. nota 7, pág. 21.

(12) Karl Popper, Conocimiento objetivo, Madrid, Tecnos, 1988, pág. 239.

(13) En rigor también Marx utilizó mecanismos de explicación/comprensión (el análisis del capital y la captación de una época, por ejemplo), lo que acerca a ambos pensadores en sus aportes al desarrollo de la teoría social, pero no teorizó sobre tales aspectos y ni siquiera los concibió bajo esos términos.

(14) Félix Gustavo Schuster, Pensamiento cientifico. Método y conocimiento en ciencias sociales. Humanismo y ciencia, Buenos Aires, ProCiencia CONICET, 1996, pág. 47.

(15) Jürgen Habermas, Conocimiento e interés, Madrid, Taurus, 1982, págs. 310 y ss., entrecomillado de la pág. 316. Nótese aquí muy especialmente que lo que aquí se denominan "juicios de valor" no refieren solamente a los "juicios evaluativos" habermasianos, sino a los mismos "juicios normativos", en el sentido de que la opción por normas no implica una mera argumentación, sino también una elección fundada en valores.

(16) Idem, págs. 317 y 319 , destacados en el original.

(17) Juan Carlos Gardella, op. cit., nota 6, pág. 43.

(18) Max Weber, op. cit., nota 2, págs. 229 y 254, respectivamente.

(19) Mario Bunge, Ética y ciencių Buenos Aires, Siglo XX, 1982, págs. 25-26.

(20) Esta distinción se basa en las sugerencias que con respecto al concepto y análisis de la ideología presenta Terry Eagleton, Ideologia. Una introducción, Barcelona, Paidós, 1997, capitulo 7 y conclusión.

(21) Otra forma de ejercicio de la valoración en Weber, correctamente destacada por Anthony Giddens, es la realización de juicios de hecho sobre la importancia o trascendencia de un acontecimiento en una cadena causal (Anthony Giddens, El capitalismo y la moderna teoria sociah Barcelona, Labor, 1994, págs. 234-237). Aquí el juicio derivaría - para Weber - de la comprobación empírica y no de la subjetividad, pretensión que también podríamos discutir pero que resulta conveniente remitir a la previa negación de la dicotomía entre hechos y valores.

(22) Cf. Max Weber, op. cit., nota 2, pág. 245. Al respecto Cueva destaca que "No hace falta, pues, que Weber se pronuncie "moralmente" en favor del capitalismo para que haya una toma de partido. basta y sobra con aparejar teóricamente los conceptos de "racionalidad" y copitalismo y analizar todo el proceso en esa perspectiva. Tampoco es menester que el autor justifique explicitamente al sistema capitalista para hacer la apología del mismo: suficiente con que lo represente como resultado de la austeridad, las privaciones y el comportamiento económicamente "racional" de la burguesía, y no como resultado 
histórico de un proceso de despojo de los productores directos". Agustín Cueva, "Intervención ideológica en las ciencias sociales", en: AA. VV., Ideologia y ciencias sociales, México, UNAM, 1979, pág. 92.

(23) En pro de una mayor brevedad, cabe aquí dejar en suspenso la distinción entre juicio y prejuicio, que también hace al tema.

(24) El ejemplo de las causas de la Primera Guerra Mundial, que ha sido evocado brevemente a otro propósito por Pierre Vilar (Introducción al trabajo de la investigación histónica, Barcelona, Crítica, 1982, págs. 20-23), puede ilustrar la opción de valor que implica una u otra respuesta en el desarrollo particular de una explicación causal. Una reconstrucción explicativa de la Primera Guerra Mundial no puede ser ajena a la discusión sobre las causas accidentales (el asesinato de Sarajevo) y las causas estructurales (la rivalidad interimperialista). Construir una explicación de la Primera Guerra implica no sólo atribuir valor a los elementos o factores que juegan en la explicación - el asesinato, el imperialismo, las intenciones de los actores, el funcionamiento del sistema de alianzas-, sino también a aquellos que se dejan de lado - v.g. la rivalidad greco-turca por el control del Egeo y el paso al Mar Negro- e inclusive a aquellos que son postulados como resultados del proceso - v.g. la repartición de las colonias alemanas-; y ello no sólo en función de una jerarquía causal o una dilucidación intencional y funcional, sino también atento a la valoración de un cierto tipo de fenómenos (jestamos dispuestos a admitir que las rivalidades interimperialistas - es decir, el imperialismo en si - causaron ocho millones de muertos e incontables sufrimientos?).

(25) Alain Guerreau, "Política/Derecho/Economia/Religión: ¿Cómo eliminar el obstáculo?”, en: Reyna Pastor (comp.), Relaciones de poder, de producción y de parentesco en la Edad Media y Moderna, Madrid, Consejo Superior de Investigaciones Cientificas, 1990, pág. 460. Hay que señalar aquí que Guerreau no utiliza el término "representación" como alternativo al de "explicación".

(26) Riccardo Scartezzini, "Las razones de la universalidad y las de la diferencia", en: Salvador Giner y Riccardo Scartezzini (comps.), Universalidad y diferenciu, Madrid, Alianza, 1996, pág. 19.

(27) Cf. v.g. Peter Winch, "Comentario", en: Robert Borger y Frank Cioffi (comps.), La explicación en las ciencias de la conducta, Madrid Alianza, 1974.

(28) Anthony Giddens, La constitución de la sociedad. Bases de la teoria de la estructuración, Buenos Aires, Amorrortu, 1995, pág. 359.

(29) Giovanni Levi, "Los peligros del geertzismo", en: AA.VV., Luz y contraluz de una historia antropológica, Buenos Aires, Biblos, 1995, pág. 77.

(30) Jürgen Habermas, Teoní de la acción comunicaliva, Buenos Aires, Taurus, 1989, pág. 100 —basado en planteos de A. Macintyre-.

(31) Michael Baxandall, Giotto and the Orators, citado por Paul Feyerabend, "Contra la inefabilidad cultural. Objetivismo, relativismo y otras quimeras", en: Salvador Giner y Riccardo Scartezzini (comps.), op. cit., nota 26 , pág. 38.

(32) Cf. I. C. Jarvie, "Comprensión y explicación en sociología y en antropología social" y "Réplica", en: Robert Borger y Frank Cioffi (comps.), La explicación en las ciencias de la conducth op. cit., nota 27.

(33) I. C. Jarvie, "Comprensión y explicación...", entrecomillados de págs. 171 y 160, destacado en el original.

(34) Terry Eagleton, Las ilusiomes del posmodernismo, Buenos Aires, Paidós, 1997, págs. 70-71.

(35) Riccardo Scartezzini, op. cit. nota 26, pág. 20.

(36) I. C. Jarvie, op. cit., nota 33, pág. 160 , destacado en el original.

(37) Pierre Bonnassie, Del esclavismo al feudalismo en Europa occidentah, Barcelona, Crítica, 1993. Edición española abreviada de La Catalogne... en: Pierre Bonnassie, Cataluña mil años atrás (siglos X-XI), Barcelona, Península, 1988.

(38) Pierre Dockés, La liberación medievah, México, FCE, 1995. Es interesante destacar que Dockés plantea también un discurso historiográfico orientado y articulado por valores. Concretamente, la pertinencia de su análisis es expresamente justificada por razones que superan la simple voluntad de conocer: el cómo y por qué se da fin a una forma concreta de relaciones sociales - la esclavitud-, es un tema relevante para quien está interesado en el fin de otra —el salariado— (Dockés, pág. 7). Y más allá de la "relación 
de valor" weberiana, las argumentaciones de este autor presentan la misma combinación de juicios de valor $\mathrm{y}$ afirmaciones positivas recuperada por Bonnassie.

(39) Pierre Bonnassie, Del esclavismo al feudalismo..., pág. 62. En los párrafos siguientes se indica entre paréntesis el número de las páginas de este mismo texto que se citan, a efectos de no dificultar la lectura. (40) Repetidamente las obras de Bonnassie aluden a las de Bloch para comentarlas o utilizarlas, pero la introducción de uno de sus artículos parece sumamente esclarecedora: "La noche del 16 de junio de 1944 moria Marc Bloch, en alguna parte de la campiña lionesa, fusilado por los nazis. Entre los numerosos textos inéditos que dejaba, había uno titulado Comment et pourquo finit l'esclavage ...." (Del esclavismo al feudalismo.., pág. 13), magnífico giro del discurso que resalta el posicionamiento político de un autor para luego recién entrar a discutir su producción historiográfica.

(41) El entrecomillado sobre la situación de tensión de las ciencias sociales es de Anthony Giddens, Las nuevas reglas del mélodo sociológico, Buenos Aires, Amorrortu, 1987, pág. 163, destacado en el original. La contraposición de dos versiones de la sociología en Jürgen Habermas, Teoría y praxis..., op. cit., nota 1. págs. 277 y ss.

(42) Terry Eagleton, Las ilusiones..., op. cit., pág. 142.

(43) Idem, pág. 136.

(44) Cornelius Castoriadis, El mundo fragmentado, Montevideo, Altamira/Nordan Comunidad, 1993, pág. 33, destacado en el original.

(45) Miguel Benasayag (con la colaboración de François Gèze), Utopía y libertad. Los derechos humanos: ¿una ideologia?, Buenos Aires, EUDEBA, 1998, pág. 72. 